Revue bibliographique pour le domaine irano-aryen

Volume 37-38-39 | 2018

Comptes rendus des publications de 2014-2016

\title{
Valentina Laviola. « Ziyārāt of Ghazni: Three Case Studies about Marble Re-Employments »
}

\section{Sandra Aube}

\section{(2) OpenEdition \\ 12 Journals}

\section{Édition électronique}

URL : http://journals.openedition.org/abstractairanica/42706

DOI : 10.4000/abstractairanica.42706

ISBN : 1961-960X

ISSN : 1961-960X

Éditeur :

CNRS (UMR 7528 Mondes iraniens et indiens), Éditions de l'IFRI

Référence électronique

Sandra Aube, « Valentina Laviola. «Ziyārāt of Ghazni: Three Case Studies about Marble Re-

Employments » », Abstracta Iranica [En ligne], Volume 37-38-39 | 2018, document 4, mis en ligne le 10 mars 2018, consulté le 10 décembre 2020. URL : http://journals.openedition.org/abstractairanica/ 42706 ; DOI : https://doi.org/10.4000/abstractairanica.42706

Ce document a été généré automatiquement le 10 décembre 2020.

Tous droits réservés 


\title{
Valentina Laviola. « Ziyārāt of Ghazni: Three Case Studies about Marble Re-Employments »
}

\author{
Sandra Aube
}

\section{RÉFÉRENCE}

Valentina Laviola. « Ziyārāt of Ghazni: Three Case Studies about Marble Re-

Employments », Eurasian Studies 13 (2015), p. 42-53.

1 Le volume 13 de la revue Eurasian Studies réunit quatre articles résultant d'un panel sur le site de Ghazni (Afghanistan), donné à l'occasion du "Symposia Iranica - First Biennial Iranian Studies Graduate Conference" à l'université de St Andrews (avril 2013). Capitale ghaznévide (977-1186), puis ghoride, occupée dès la période bouddhique et jusqu'aux temps modernes, Ghazni avait fait l'objet d'investigations archéologiques entre 1957 et 1978 par la Mission Archéologique Italienne en Afghanistan. Depuis lors, l'accès au site est cependant devenu extrêmement limité. En s'appuyant sur les archives photographiques et sur le matériel collecté au cours de ces anciennes campagnes, Agnese Fusaro, Viola Allegranzi, Valentina Laviola et Martina Massullo, toutes membres du projet «Islamic Ghazni. An IsIAO Archaeological Project in Afghanistan » dirigé par Roberta Giunta (IsIAO/«L'Orientale », 2004-), offrent des données nouvelles et très attendues sur l'histoire de ce site d'envergure.

2 Le troisième article de cette série est consacré aux remplois de marbres sculptés dans les ziyārāt de Ghazni. Valentina Laviola dénombre 20 exemples à Ghazni de remplois de marbres ghaznévides et ghorides dans des structures funéraires. Il s'agit de panneaux décoratifs en marbre provenant du palais ou d'éléments de tombes. Ces remplois ont été effectués après la conquête mongole, c'est-à-dire à une période où la cité connaissait un déclin par rapport à l'apogée ghaznévide. Laviola développe trois exemples de remplois parmi les plus significatifs : ceux des ziyārāt de Sultan Ibrāhīm, de 
Pir-i Falizvan et de 'Abd al-Salām. Elle démontre que ces remplois ont une visée décorative, mais aussi commémorative, en s'attachant le passé prestigieux de Ghazni, à la manière de trophées. En marquant le caractère spirituel de ces remplois, Laviola rappelle ainsi que le site de Ghazni était progressivement devenu une vaste ère funéraire et cultuelle.

\section{AUTEURS}

\section{SANDRA AUBE}

CNRS, Mondes iranien et indien, Paris 